Letter to the Editor

\title{
Simultaneous presentation of hereditary hyperferritinaemia cataract syndrome and hereditary haemochromatosis
}

\author{
Katia A Maccora, ${ }^{1 *}$ Emmanuelle Souzeau PhD, ${ }^{2 *}$ Jonathan B Ruddle FRANZCO ${ }^{3}$ and \\ Jamie E Craig DPhil FRANZCO²
}

1. Monash University Faculty of Medicine Nursing and Health Sciences, Clayton, Victoria, Australia

2. Department of Ophthalmology Flinders University, Flinders Medical Centre, Adelaide, SA, Australia

3. Department of Ophthalmology University of Melbourne, Parkville, Victoria, Australia

* These authors contributed equally to this work

Correspondence: Jonathan B Ruddle, Department of Ophthalmology University of Melbourne, Parkville, Victoria, Australia

Email: jbruddle@gmail.com

Received 4 April 2017; accepted 16 April 2018

Conflict of interest: None

Funding sources: None

This is the author manuscript accepted for publication and has undergone full peer review but has not been through the copyediting, typesetting, pagination and proofreading process, which may lead to differences between this version and the Version of Record. Please cite this article as doi: $10.1111 /$ ceo.13318

This article is protected by copyright. All rights reserved. 
Hereditary hyperferritinaemia cataract syndrome (HHCS, OMIM 600886) is a rare autosomal dominant disorder characterised by early cataract formation and isolated high serum ferritin. Typical cataracts in HHCS are of a distinctive morphology characterised by progressive axial and peripheral white flecks with small crystalline aggregates ${ }^{1}$. HHCS is caused by variants in the iron-responsive element (IRE) of the Ferritin Light Chain (FTL) gene (OMIM 134790) which disrupt binding of the inhibitory iron regulation protein to the IRE loop, leading to excessive dysregulated serum ferritin production. Ferritin is a large iron cellular storage protein, and accumulation in the lens fibres is suspected to be responsible for the aetiology of cataract formation in HHCS. HHCS often presents by the second decade of life and has a minimum prevalence of approximately $1 / 200,000$, although this is likely an underestimate ${ }^{1}$. HHCS is often biochemically mistaken for haemochromatosis, as hyperferritinaemia can suggest iron overload ${ }^{2}$.

Hereditary haemochromatosis (OMIM 235200) is a disorder of iron metabolism, affecting $1 / 200$ to $1 / 400$ individuals, and is due to autosomal recessive variants in the hereditary Fe (HFE) gene (OMIM 613609)2. p.Cys282Tyr is the most common variant, accounting for $90 \%$ of cases $^{2}$ and has a carrier rate of $1 / 10$ in the Caucasian population ${ }^{3}$.Transferrin, the iron transport protein found in plasma, is useful in the detection of iron overload. Hereditary haemochromatosis is clinically suspected in individuals with elevated transferrin saturation $(>50 \%)$, and confirmed with genetic testing ${ }^{3}$.

While both HHCS and hereditary hemochromatosis are associated with raised serum ferritin, they are distinct conditions of separate aetiology, and individuals with HHCS do not have iron overload. This case presents a family with two individuals affected with HHCS, one with a unique diagnostic dilemma of simultaneous HHCS and hereditary haemochromatosis. 
A 35-year-old woman (Figure 1A, II1) presented with longstanding, progressively worsening glare symptoms and poor distance vision. Examination revealed bestcorrected visual acuities of right $6 / 15$ and left 6/48, left amblyopia and bilateral central speckled cataracts. The pathognomonic appearance of the cataracts on slit lamp retroillumination (Figure $1 B$ and C) and high ferritin level of 1200ug/L (normal 15-300ug/L) were consistent with a clinical diagnosis of HHCS. Bilateral cataract surgery was performed. Additionally, she was diagnosed with hereditary haemochromatosis at the age of 29 years. As a regular blood donor, three-monthly venesections normalised her transferrin saturation, however, her serum ferritin remained persistently elevated.

Figure 1. Pedigree of the family (A). Black symbols; HHCS, grey symbols; haemochromatosis; arrow; proband, +; variant, -; wild type allele. Slit-lamp photography of the proband using direct illumination (B) and transillumination (C) of the cataract in her right eye showing scattered central and peripheral flecks.

By the age of 4 years, her son (III1) required bilateral cataract surgery for increasing visual difficulties, esotropia and photophobia due to progressive congenital cataracts. The mother of the proband had a normal eye examination and the father was deceased. The proband's paternal grandmother was reported to have poor vision but could not be examined.

Written informed consent was obtained in all participants and the study was approved by the southern Adelaide Clinical Human Research Ethics Committee. Blood derived DNA samples were collected for the proband (II1), her mother (I2) and her son (III1), and the IRE of the FTL gene and the HFE gene were directly sequenced. 
A heterozygous sequence variant (c.-168G $>T$, rs398124635) was identified in the FTL gene in the proband and her son (Figure 1A). This variant has been reported in other families with $\mathrm{HHCS}^{1}$. It was absent from the mother (I2) and the father (I1) could not be tested. The proband was also homozygous for the common p.Cys282Tyr variant (c.845G >A, rs1800562) in the HFE gene causing hereditary haemochromatosis. Her son and her mother were heterozygous for the HFE variant.

To the best of our knowledge, this is the first documented case of co-inherited HHCS and hereditary haemochromatosis in Australia.

HHCS commonly presents as a childhood or adolescent onset of cataract with gradual development of glare symptoms. Since first described in 1995, there have been 37 variants reported in the IRE of the FTL gene associated with $\mathrm{HHCS}^{4}$. The high ferritin levels do not cause any clinical symptoms apart from those due to cataract, and there are no other known clinical or pathological manifestations of $\mathrm{HHCS}^{5}$. Individuals with HHCS are often misdiagnosed as having haemochromatosis due to high ferritin levels and often undergo inappropriate venesection that can lead to iron deficiency.

The unique presence of both HHCS and hereditary haemochromatosis presents a challenge for diagnosis and management. It highlights the need for ophthalmological examination of patients with elevated ferritin and visual disturbance, as these patients may have undiagnosed HHCS. Patients labelled with haemochromatosis who have cataracts characteristic of HHCS should have genetic testing for both disorders, as cataract is not specifically associated with haemochromatosis. It is expected that ophthalmologists may encounter HHCS more frequently with increasing awareness and documentation of cases. The morphology of the associated cataract is almost 
pathognomonic of HHCS to an experienced observer. Improved diagnostic accuracy will allow appropriate genetic counselling and more appropriated management.

\section{Acknowledgements}

Alex W Hewitt, Miles H Prince 


\section{REFERENCES}

1. Craig JE, Clark JB, McLeod JL, et al. Hereditary hyperferritinemia-cataract syndrome: prevalence, lens morphology, spectrum of mutations, and clinical presentations. Arch Ophthalmo/ 2003; 121:1753-61.

2. McLaren GD, Gordeuk VR. Hereditary hemochromatosis: insights from the Hemochromatosis and Iron Overload Screening (HEIRS) Study. Hematology Am Soc Hematol Educ Program. 2009: 195-206.

3. Adams PC. Epidemiology and diagnostic testing for hemochromatosis and iron overload. Int J Lab Hemato/2015; 37 Suppl 1:25-30.

4. Luscieti S, Tolle G, Aranda J, et al. Novel mutations in the ferritin-L ironresponsive element that only mildly impair IRP binding cause hereditary hyperferritinaemia cataract syndrome. Orphanet J Rare Dis 2013; 8: 30.

5. Bowes O, Baxter K, Elsey T, Snead M, Cox T. Hereditary hyperferritinaemia cataract syndrome. Lancet 2014; 383(9927):1520. 


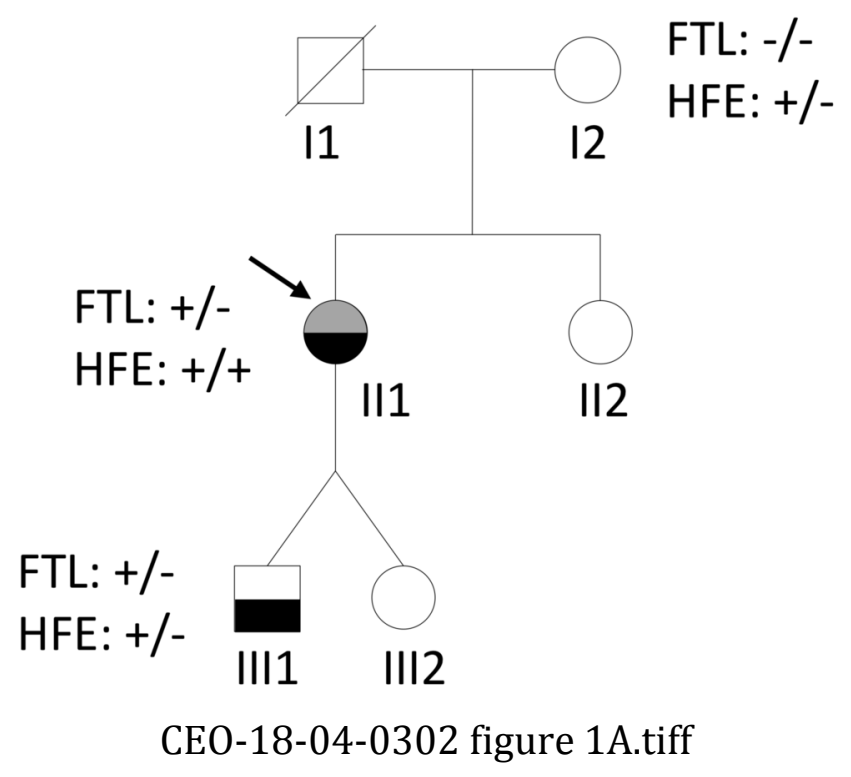

This article is protected by copyright. All rights reserved. 


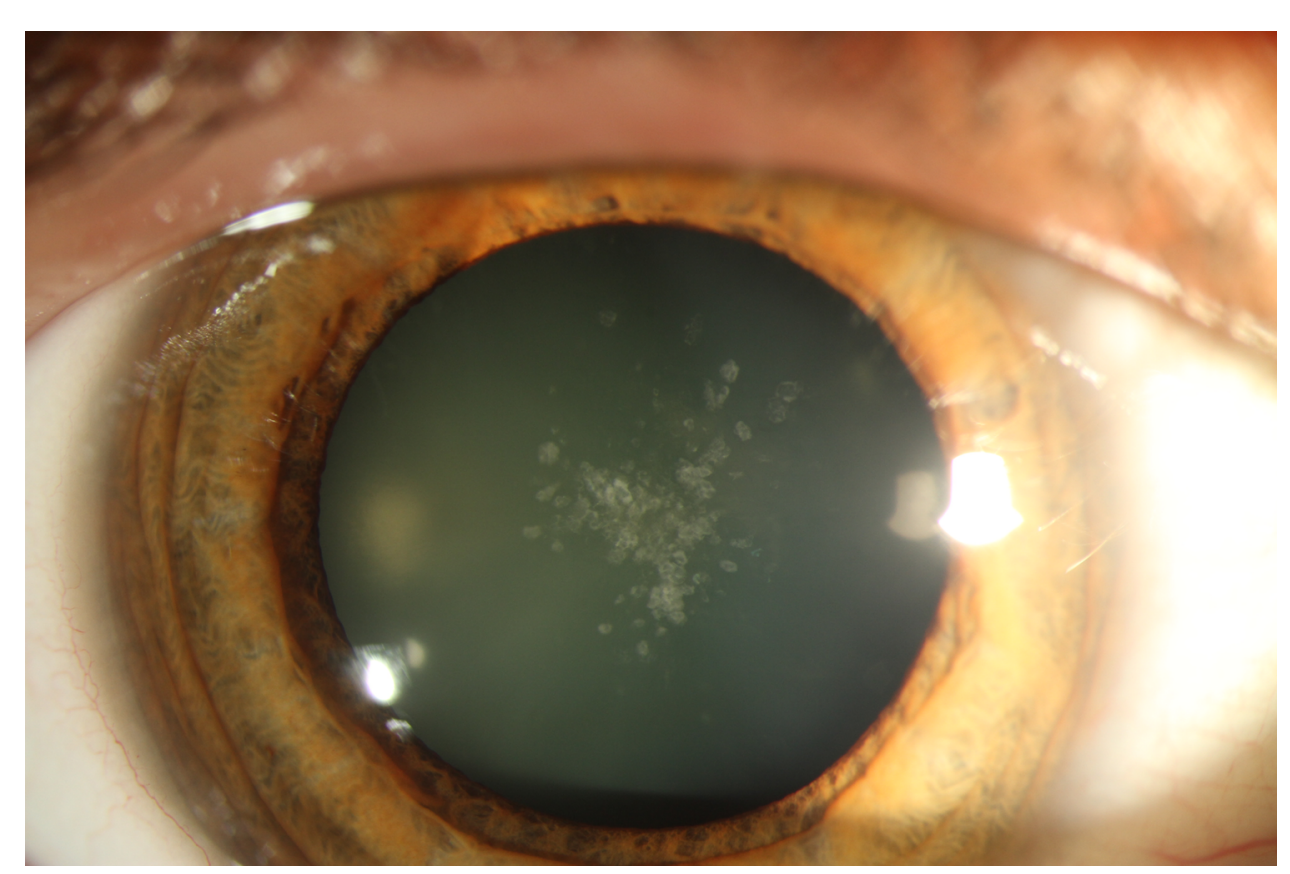

CE0-18-04-0302 figure 1B.tif

This article is protected by copyright. All rights reserved. 


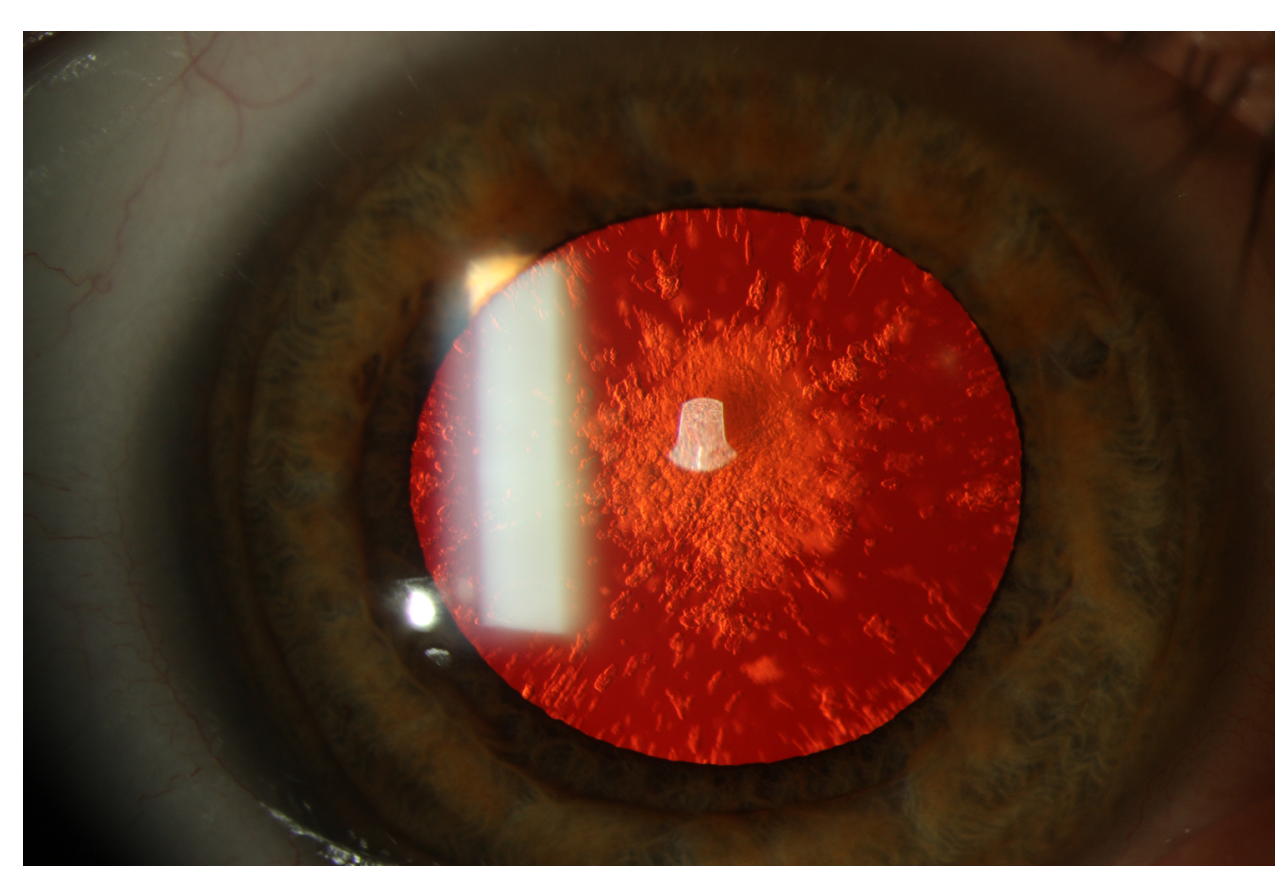

CE0-18-04-0302 figure 1C.tif

This article is protected by copyright. All rights reserved. 


\section{University Library}

\section{- MINERVA \\ A gateway to Melbourne's research publications}

Minerva Access is the Institutional Repository of The University of Melbourne

Author/s:

Maccora, KA;Souzeau, E;Ruddle, JB;Craig, JE

Title:

Simultaneous presentation of hereditary hyperferritinaemia cataract syndrome and hereditary haemochromatosis

Date:

2018-11-01

Citation:

Maccora, K. A., Souzeau, E., Ruddle, J. B. \& Craig, J. E. (2018). Simultaneous presentation of hereditary hyperferritinaemia cataract syndrome and hereditary haemochromatosis.

CLINICAL AND EXPERIMENTAL OPHTHALMOLOGY, 46 (8), pp.962-964. https:// doi.org/10.1111/ceo.13318.

Persistent Link:

http://hdl.handle.net/11343/284043 